\title{
Performing easy prone punction
}

\author{
Ramón Cansino, Alejandra Portilla, Juan Gómez Rivas \\ Department of Urology, Hospital Universitario La Paz, Madrid, Spain \\ Citation: Cansino R, Portilla A, Gómez Rivas J. Performing easy prone punction. Cent European J Urol. 2017; 70 : $170-174$.
}

Article history

Submitted: Oct. 20, 2016

Accepted: April 17, 2017

Published online: June 7, 2017

Corresponding author

Ramón Cansino

Hospital Universitario

La Paz 261 Paseo

La Castellana

28046 Madrid, Spain

phone: +34 617558602

urocansino@yahoo.es
Introduction Percutaneous renal surgery has been considered one of the most important advances in urology. There are several possibilities to perform a kidney puncture such as using fluoroscopy, ultrasound or both. The aim of this article is to describe our puncture technique.

Material and methods Correct puncture is one of the most critical and challenging steps during percutaneous surgery. Bull's eye technique and other similar techniques supported by fluoroscopy try to make triangulations and provide different views. On the other hand, many urologists prefer the usage of ultrasound to help reach the calyx. The perfect puncture could also be a scanner guided puncture.

Results Under general anesthesia, cystoscopy is performed for ureteral catheter placement. The excretory system is opacified by administering contrast to the ureteral catheter. Perpendicular puncture on the selected calyx is done; this is a $90^{\circ}$ puncture with a fine spinal needle $20 \mathrm{G}$ into the selected calyx under fluoroscopy control to visualize the correct penetration into the calyx. Moving forward to the next step, an $18 \mathrm{G}$ needle is used to follow the correct calyx - infundibulum - renal pelvis path. The goal is to put together both tips of the 2 needles (needle Kiss technique).

Conclusions After several years of performing percutaneous surgery, we conclude that our technique can facilitate the prone position puncture thanks to the information given from the thin needle while simultaneously minimizing the use of fluoroscopy for triangulation maneuvers and avoiding the use of ultrasound to determine the depth of the target calyx.

\section{Key Words: percutaneous nephrolithotomy (' prone ‘) lithiasis}

\section{INTRODUCTION}

Percutaneous renal surgery has been considered one of the most important advances in urology. Back in 1955 it was described as the use of a needle to decompress a kidney with hydronephrosis [1, 2]; but it was not until 1976, when Fernstrom and Johansson [3] succeeded in removing nephrolithiasis through a percutaneous tract for the first time, that percutaneous surgery began to develop. With the description of the technique according to the experience of Alken [4] and later Segura [5], there was a breakthrough in the universalization of standardized technical steps in prone percutaneous nephrolithotomy.

There are various methods to perform a kidney puncture, such as fluoroscopy, ultrasound or both.

If fluoroscopy is the chosen method, a triangulation must be done to know the depth of the target calyx, this is due to having only two space planes and the third plane (depth) being unknown. Nevertheless, this triangulation leads to the possibility of consuming more fluoroscopy time and radiation exposure than desired.

If ultrasound is used, the depth of the target calyx might be known, but fluoroscopy is needed to identify if the puncture is going through the correct axis from calyx to renal pelvis. When checking on fluoroscopy after ultrasound puncture we might occasionally observe a puncture in the urinary tract through the infundibula rather than through the calyx.

The aim of this article is to describe our puncture technique. We believe it can help systematize and simplify the puncture technique in prone position while giving non-expert urologists the opportunity to improve their rates of success in the procedure. 


\section{Evidence acquisition}

Correct puncture is one of the most critical and challenging steps during percutaneous surgery. It is the responsibility of the urologist to decide which technique is suitable for each patient and select between prone or supine position, taking into consideration the surgeon's experience and certain patient characteristics such as obesity, horseshoe kidney and others. Valdivia et al. [6-9] first described the performance of percutaneous renal surgery in the supine position. This approach was modified years later by Ibarlucea et al. $[10,11,12]$.

Both techniques are widely accepted and have helped to expand percutaneous renal surgery, especially when Scoffone et al. [13-16] achieved the combination of endoscopic intrarenal surgery (ECIRS) with percutaneous renal surgery in supine position, which was a breakthrough in this field.

Percutaneous nephrolithotomy gained popularity in the early 80's with the advent of lithotripsy (ESWL) restricted indications. Currently, recognizing the limitations of ESWL for the treatment of stones more than $2 \mathrm{~cm}$ [17], percutaneous surgery is again excelling in the treatment of diseases of the upper urinary tract, especially with the new variety of small caliber accesses with gauges ranging from $4.8 \mathrm{Fr}, 8.10,12,14,16,18,20,22$ and more [18, 19]. The steps for proper percutaneous puncture are described, based and supported by fluoroscopy, ultrasound, or both.

Bull's eye technique and the use of ultrasound to support the percutaneous puncture are widespread and well-known techniques [20]. These and other simi-

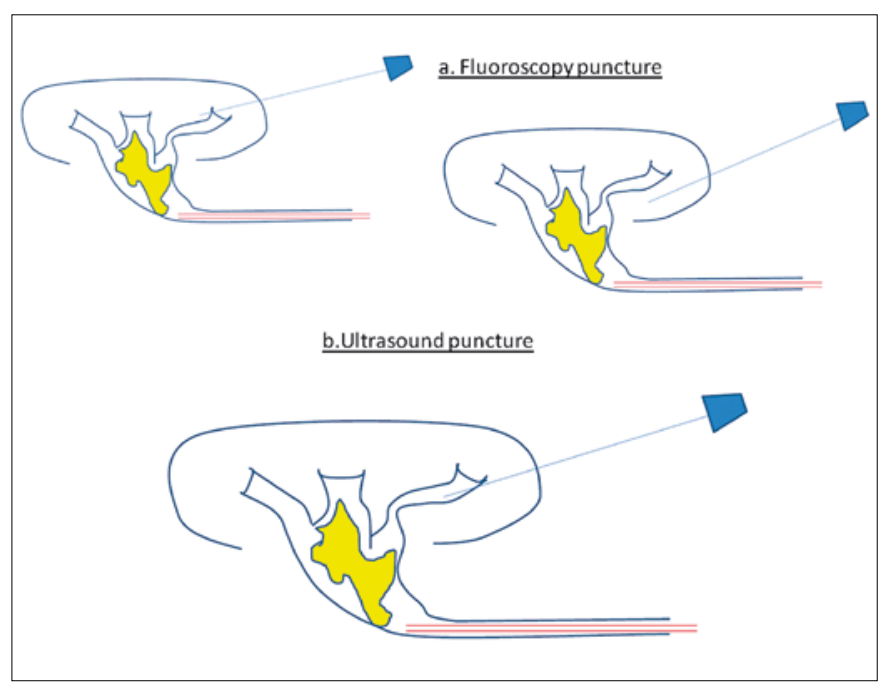

Figure 1. A. With fluoroscopy, the depth of the calyx can be missed. 1B. With ultrasound, the puncture can go through the infundibula. lar techniques supported by fluoroscopy try to make triangulations and provide different views, helping in identifying the inclination or orientation that the needle should adopt to perform a correct papillary puncture, this is due to the challenging step that involves knowing the depth of the target calyx to go through the papilla.

The use of fluoroscopy and/or ultrasound is a key point in percutaneous surgery. One of the most important and difficult steps is the puncture through the papilla. In our institution, we strive to follow the traditional principles of percutaneous renal puncture, such as making a puncture focused on the cup of the calyx and being precise during percutaneous dilation to avoid vascular injury.

Recent literature published by Kyriazis and Liatsikos, states that the location of the puncture is not so crucial, and sometimes, it is possible to make it directly into the stone, without going through the calyx $[21,22]$. In very experienced hands, this technique could probably work quite well, but it might be too soon to spread it among all urologists. Time and further research will give us the answer.

On the other hand, many urologists prefer the usage of ultrasound to help reach the calyx. With the aid of ultrasound, urologists can easily determine the depth of the calyx, and thus the angle of the needle needed to reach the calyx or the urinary tract. Also, ultrasound provides us with information about the location of the bowel, pleura and solid organs (lung, liver and spleen) [23]. One of the major drawbacks regarding ultrasound lies in the process of checking the puncture with fluoroscopy, where, in some cases, the puncture could be inside the urinary tract, not

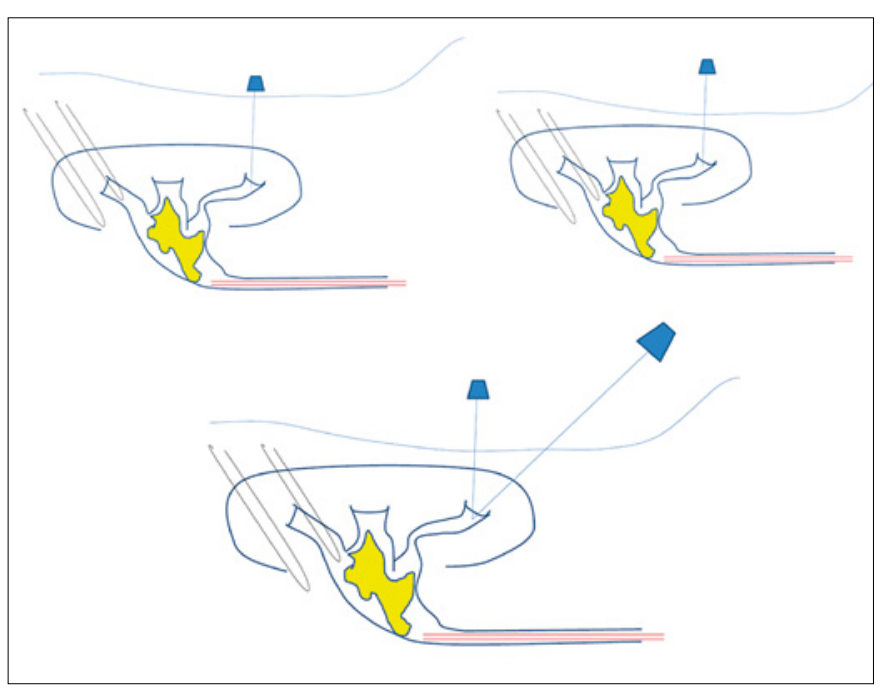

Figure 2. The thin needle informs us if the calyx is deep or superficial and if the tips of both needles can join. 


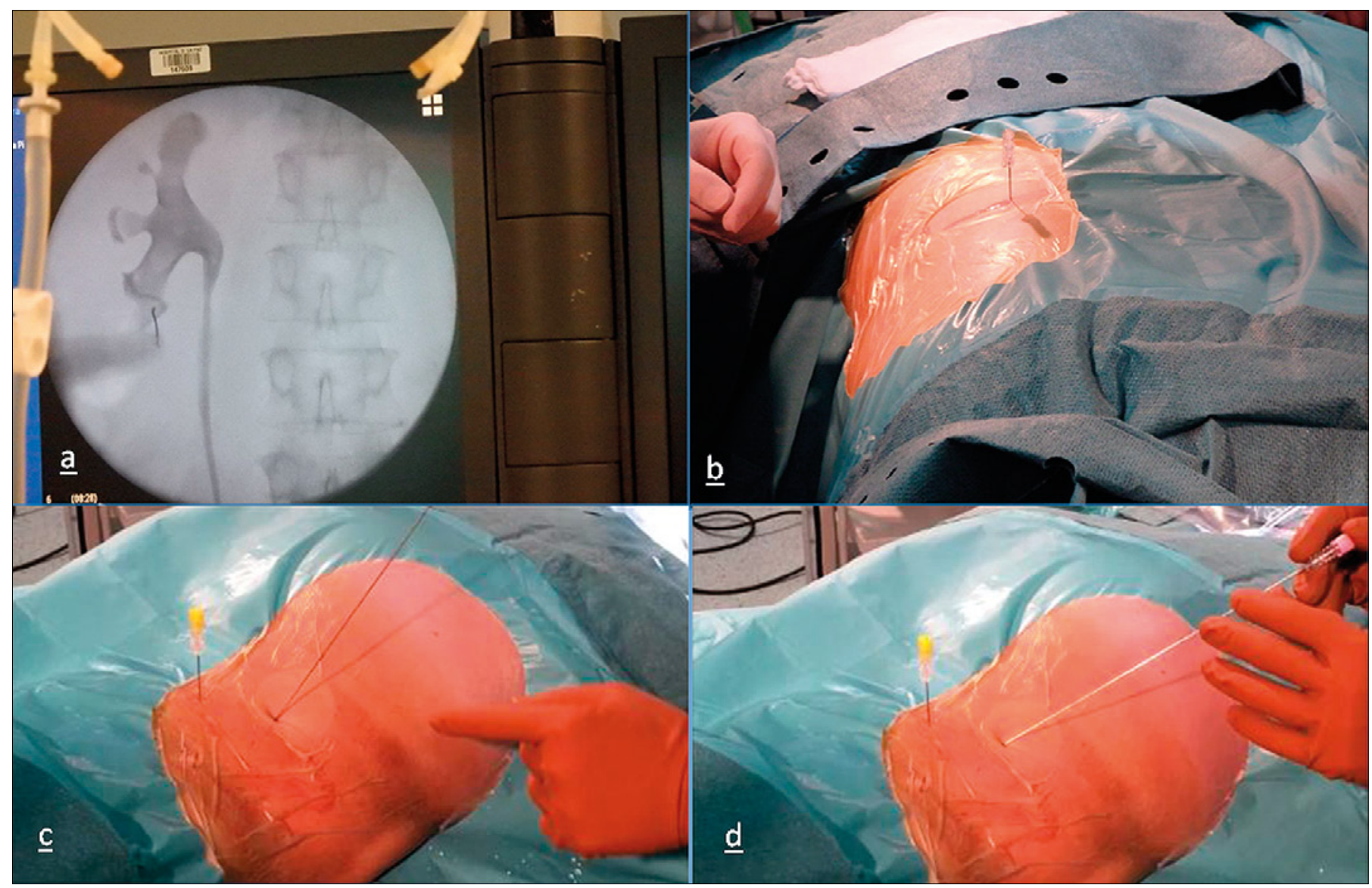

Figure 3. A. Perpendicular puncture of the calyx. B. Checking urine outflow. CD. Modifying the incline angle of the working needle according to the thin needle.

through the papilla but maybe through the infundibulum and the puncture would need to be repeated since going ahead and performing dilatation could lead to vascular injury (Figure 1).

The perfect puncture could be a scanner guided puncture. There are several publications explaining that possibility, but of course this is not useful in daily practice and the radiation exposure of the patient is another important issue [24].

Dybowski et al. [25] recommend to avoid or prevent complications by the creation of centers of excellence (stone centers) and to improve teaching techniques by using virtual reality technologies and simulators. Another method for performing an easier puncture is the endovision technique, combining the vision of the retrograde intrarrenal surgery from a flexible ureteroscope and viewing how the percutaneous needle is coming through the papilla [26, 27]. This technique, published by Scoffone et al. gives us a very precise image when the needle is in the correct site, but by using the flexible ureteroscope it is not possible to guide the puncture, it only allows us to see if the needle has come into the right or wrong site.
As it has been shown so far, there are several options to choose from when performing the puncture. Percutaneous surgery has been performed in our department since the 1980's and the aim of this review is to show one of the easiest and more useful ways to execute the puncture in the prone position. We find our technique easy to be performed by all groups of urologists: experienced and novice alike.

\section{Technique}

\section{Patient positioning}

Under general anesthesia and in the lithotomy position, cystoscopy is performed for ureteral catheter placement. An open-end tip $7 \mathrm{Fr}$ is placed, to opacify the collecting system with contrast, facilitating percutaneous puncture.

Later, in the prone position, protections are placed under the chest, shoulders, arms, knees and ankles to prevent decubitus injuries. A pillow under the abdomen is also placed in order to lift up the kidney. 


\section{Selecting the puncture site}

The excretory system is opacified after administering contrast to the ureteral catheter. The collecting system is inspected with the upright X Ray C-arm and the best calyx for percutaneous surgery is then identified and selected.

Perpendicular puncture of the selected calyx is done; this is a $90^{\circ}$ puncture with a fine $20 \mathrm{G}$ spinal needle into the selected calyx under fluoroscopy control to visualize the correct penetration into the calyx (Figures 2, 3).

The correct location of the needle inside the calyx is well-known for various reasons:

- The calyx contrast viewed in retrograde pyelography moves (fovea effect) and this occurs when the needle penetrates into the calyx.

- Urine /contrast output occurs when removing the stylet of the needle.

- The subtle movement of the needle from side to side, 'drags' the urinary tract viewed by fluoroscopy.

With this puncture, we intend to determine the depth of the selected calyx. Fluoroscopy gives two-dimensional information and if the depth is not known, support techniques are needed, like Bull's eye, triangulation or ultrasound, as already described above. In this case, it is the perpendicular needle, which helps to establish the depth or the fluoroscope's third dimension.

Moving forward to the next step, an $18 \mathrm{G}$ needle is used to follow the desired calyx- infundibulum- renal pelvis path, which will be in the right direction. The incline and the angle of the needle will vary in each case and according to what the perpendicular needle is reporting back to us. A fine perpendicular needle, which will be very deep, will inform of the calyx depth, and therefore one should broaden the angle of the $18 \mathrm{G}$ needle as needed with respect to the horizontal plane of the patient. On the other hand, the fine, perpendicular, very superficial needle, suggests that we put our $18 \mathrm{G}$ needle very close to the patient, at a more acute angle, meaning that the calyx cup is more superficial (Figures 2,3 ).

The goal is to put together both tips of the two needles (needle Kiss technique) (Figure 4). As it is known, when the fine perpendicular needle is already inside the calyx, if we are able to touch the tip of the fine perpendicular needle with the tip of the $18 \mathrm{G}$ needle or at least join both tips as much as possible, we will

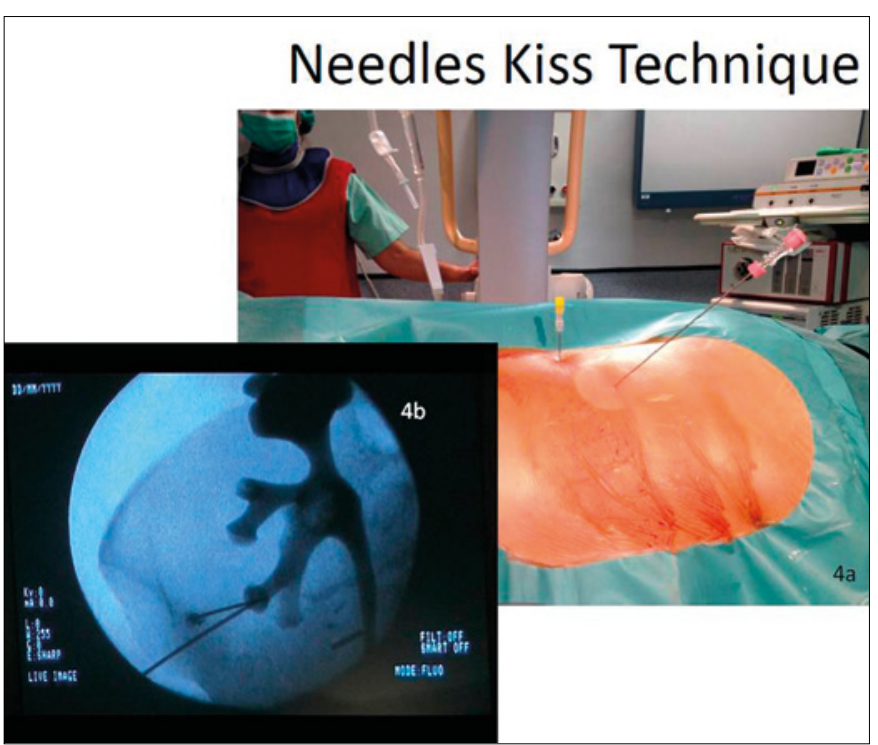

Figure 4. AB. Both needles join at their tips: A. Patient.

B. Fluoroscopy image in another patient.

have a safe and easy approach to the selected calyx. However, nobody is perfect, and if the proper puncture is not performed, we simply have to slide in an $\mathrm{X}$ Ray bow at $30^{\circ}$ below the operating table. If the $18 \mathrm{G}$ needle is below the reference needle (fine needle), this means that the puncture has been made at a too large angle. In this situation, we need to slightly remove the $18 \mathrm{G}$ needle and change the position going in at a more acute angle in order to make a more superficial puncture. Then, both tips should finally be joined, and the correct needle position can be checked by removing the stylet and identifying urine / contrast output. Logically, the opposite has to be performed if the $18 \mathrm{G}$ needle tip is above the reference needle tip.

\section{CONCLUSIONS}

After several years of performing percutaneous surgery, we conclude that our technique can facilitate the prone position puncture thanks to the information given from the thin needle minimizing the use of the fluoroscopy to do triangulation maneuvers and avoiding the use of ultrasound to know the depth of the target calyx.

\section{CONFLICTS OF INTEREST}

The authors declare no conflicts of interest. 


\section{References}

1. Casey WC, Goodwin WE. Percutaneous antegrade pyelography and hydronephrosis; direct, intrapelvic injection of urographic contrast material to secure a pyeloureterogram after percutaneous needle puncture and aspiration of hydronephrosis. J Urol. 1955; 74: 164-173.

2. Goodwin WE, Casey WC, Woolf W. Percutaneous trocar (needle) nephrostomy in hydronephrosis. J Am Med Assoc. 1955; 157: 891-894.

3. Fernstrom I, Johansson B. Percutaneous pyelolithotomy: a new extraction technique. Scand J Urol Nephrol. 1976; 10: 257-259.

4. Alken P, Hutschenreiter G, Guenther R. Percutaneous kidney stone removal. Eur Urol. 1982; 8: 304-331.

5. Segura JW, Patterson DE, LeRoy AJ, et al. Percutaneous removal of kidney stones: review of 1,000 cases. J Urol. 1985; 134 : 1077-10781.

6. Valdivia Uría JG, Lachares Santamaría E, Villarroya Rodríguez S, Taberner Llop J, Abril Baquero G, Aranda Lassa JM. Percutaneous nephrolithectomy: simplified technique (preliminary report). Arch Esp Urol. 1987; 40: 177-180.

7. Valdivia JG, Valle J, Villarroya S. Why is percutaneous nephroscopy still performed with the patient prone? J Endourol. 1990; 4: 269-272.

8. Valdivia Uría JG, Valle Gerhold J, López López JA, et al. Technique and complications of percutaneous nephroscopy: experience with 557 patients in the supine position. J Urol. 1998; 160: 1975-1978.

9. Valdivia JG1, Scarpa RM, Duvdevani M, et al. Supine versus prone position during percutaneous nephrolithotomy: a report from the Clinical Research Office of the Endourological Society Percutaneous Nephrolithotomy Global Study. J Endourol. 2011; 25: 1619-1625.

10. Ibarluzea González G, Gamarra Quintanilla M, Gallego Sánchez JA,
Pereira Arias JG, Camargo Ibargaray I, Bernuy Malfaz C. Percutaneous kidney lithotripsy. Clinical course, indications and current methodology in our Lithotripsy unit. Arch Esp Urol. 2001; 54: 951-969.

11. Ibarluzea G, Scoffone CM, Cracco CM, et al. Supine Valdivia and modified lithotomy position for simultaneous antegrade and retrograde urological access. BJU Int. 2007; 100: 233-236.

12. Ibarluzea JG, Gamarra MG, Leibar A, Pereira JG. The evolution from prone to supine PNL and from supine PNL to ECIRS: the basque history of endourology. In: Scoffone CM, Hoznek A, Cracco CM, eds. Supine percutaneous nephrolithotomy and ECIRS. Springer France; 2014. pp. 15-23.

13. Scoffone CM, Cracco CM, Cossu M, Grande S, Poggio M, Scarpa RM. Endoscopic combined intrarenal surgery in Galdakao-modified supine Valdivia position: a new standard for percutaneous nephrolithotomy? Eur Urol. 2008; 54: 1393-1403.

14. Cracco CM, Scoffone CM. ECIRS (Endoscopic Combined Intrarenal Surgery) in the Galdakao-modified supine Valdivia position: a new life for percutaneous surgery? World J Urol. 2011; 29: 821-827.

15. Scoffone CM, Cracco CM, Scarpa RM. Endoscopic Combined IntraRenal Surgery (ECIRS): rationale. In: Scoffone CM, Hoznek A, Cracco CM, eds. Supine percutaneous nephrolithotomy and ECIRS. France: Springer; 2014, pp. 99-108.

16. Hoznek A, Daels FPJ, Kimuli N'Tege, et al. ECIRS: patient positioning and organization of the operating room. In: Scoffone CM, Hoznek A, Cracco CM, editors. Supine percutaneous nephrolithotomy and ECIRS. France: Springer; 2014, pp. 109-125.

17. Türk C, Knoll T, Petrik A, et al. Guidelines on Urolithiasis. European Association of Urology 2016. http://uroweb.org/ wp-content/uploads/EAU-GuidelinesUrolithiasis-2016.pdf
18. Shah AK, Xu K, Liu H, et al. Implementation of ultramini percutaneous nephrolithotomy for treatment of $2-3 \mathrm{~cm}$ kidney stone: a preliminary report. J Endourol. 2015; PMID 26122916.

19. Desai MR, Sharma R, Mishra S, Sabnis RB, Stief C, Bader M. Singlestep percutaneous nephrolithotomy (microperc): the initial clinical report. J Urol. 2011; 186: 140-145.

20. Ko R, Soucy F, Denstedt JD, Razvi H. Percutaneous nephrolithotomy made easier: a practical guide, tips and tricks BJU Int. 2007; 101: 535-539.

21. Kyriazis I, Kallidonis P, Vasilas $M$, Panagopoulos V, Kamal W, Liatsikos E. Challenging the wisdom of puncture at the calyceal fornix in percutaneous nephrolithotripsy: feasibility and safety study with 137 patients operated via a non-calyceal percutaneous track. World J Urol. 2016; 35: 795-801.

22. Liatsikos EA, Kapoorb R, Lee B, et al. Angular Percutaneous Renal Access. MultipleTracts Through a Single Incision for Staghorn Calculous. Treatment in a Single Session. Eur Urol. 2005; 48: 832-837.

23. Knoll T, S. Michel M, Alken P. Percutaneous nephrolithotomy: the Mannheim technique. BJU Int. 2007; 99: 213-231.

24. Rassweiler J, Rassweiler MC, Klein J. New technology in ureteroscopy and percutaneous nephrolithotomy. Curr Opin Urol. 2016; 26: 95-106.

25. Dybowski B. Getting Access in PNLEyes wide shut. Cent European J Urol. 2014; 67: 193-194

26. Miano R, Scoffone C, De Nunzio C, Germani S, Cracco C, et al. Position: prone or supine is the issue of percutaneous nephrolithotomy. J Endourol. 2010; 24: 931-938.

27. Scoffone CM, Cracco CM, Poggio M, Scarpa RM. Endoscopic combined intrarrenal surgery for high burden renal stones. Arch Ital Urol Androl. 2010; 82: 41-42. 